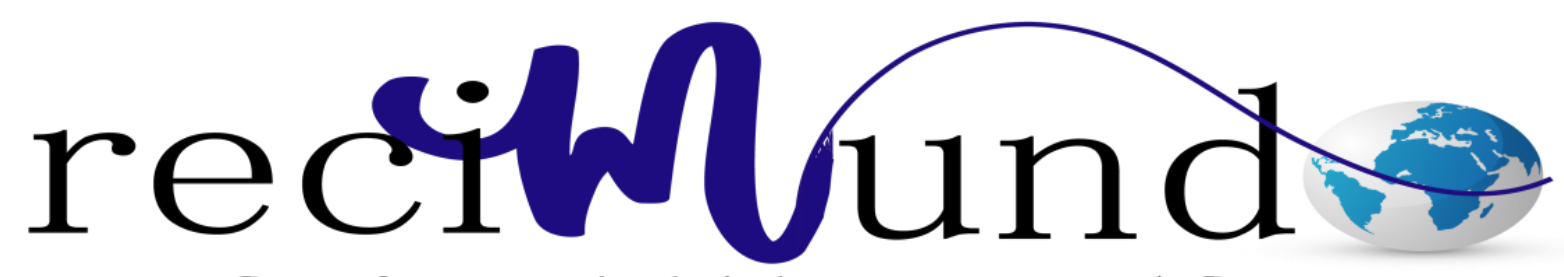

Revista Cientifica Mundo de la Investigación y el Conocimiento

Briones Núñez Nicolás David a; Ortiz Samaniego Juan Andrés ${ }^{\text {b; }}$ Suqui Romero Gabriel Yovany ${ }^{\mathrm{c}}$

La vulneración a la tutela judicial efectiva por la imputación incorrecta de un delito

The vulnerability to effective judicial tutelage for the incorrect imputation of a crime

Revista Científica Mundo de la Investigación y el Conocimiento. Vol. 3 núm.1, enero, ISSN: 2588-073X, 2019, pp. 126-150

DOI: 10.26820/recimundo/3.(1).enero.2019.126-150

URL: $\underline{\text { http://www.recimundo.com/index.php/es/article/view/361 }}$

Editorial Saberes del Conocimiento

Recibido: 20/11/2018

Aceptado: 05/01/2019

Publicado: 31/01/2019

Correspondencia: nbriones_est@utmachala.edu.ec

a. Universidad Técnica de Machala; nbriones_est@utmachala.edu.ec

b. Universidad Técnica de Machala; jaortizs_est@utmachala.edu.ec

c. Universidad Técnica de Machala; Docente Titular de Derecho Penal; gsuqui @utmachala.edu.ec 


\section{La vulneración a la tutela judicial efectiva por la imputación incorrecta de un \\ delito}

Vol. 3, núm. 1., (2019)

Briones Núñez Nicolás David; Ortiz Samaniego Juan Andrés; Suqui Romero Gabriel Yovany

\section{RESUMEN}

Garantizada en la Constitución de la República del Ecuador, la Tutela Judicial Efectiva es objeto de observación por parte de las autoridades judiciales, puesto que tiene el carácter de resguardar los derechos de las personas frente a posibles arbitrariedades. Este artículo aborda el estudio a nivel procesal de dicha garantía la que está latente en el acceder al sistema de justicia, durante el proceso que observe las garantías básicas y en la respuesta fundada en derecho que debe ejecutarse. El presente estudio sustentado en la revisión bibliográfica especializada, jurisprudencia y normativa legal con el empleo del método analítico, comparativo y exegético, y luego de analizar las variables pertinentes, concluye que los fiscales al igual que los jueces, están llamados u obligados a garantizar la Tutela Judicial Efectiva pues, son los responsables de velar por el cumplimiento de este derecho de protección para la víctima. Al analizarse las variables que encierran la problemática, se puede observar una posible vulneración a la Tutela Judicial Efectiva por parte de Fiscalía en base a un potencial error en la valoración del tipo penal durante la formulación cargos, lo que terminó por afectar por cuestiones de prescripción del ejercicio privado de la acción el derecho de la víctima a una Tutela Judicial Efectiva por la incorrecta actuación fiscal.

Palabras Claves: Tutela Judicial Efectiva; Asesinato; Lesiones; Tentativa; Nexo Causal. 


\title{
La vulneración a la tutela judicial efectiva por la imputación incorrecta de un delito
}

Vol. 3, núm. 1., (2019)

Briones Núñez Nicolás David; Ortiz Samaniego Juan Andrés; Suqui Romero Gabriel Yovany

\begin{abstract}
Guaranteed in the Constitution of the Republic of Ecuador, effective judicial protection is subject to observation by the judicial authorities, since it has the character of protecting the rights of individuals against possible arbitrariness. This article deals with the procedural level of this guarantee that is latent in accessing the justice system, during the process that observes the basic guarantees and in the response based on the right that must be executed. The present study based on the specialized bibliographic review, jurisprudence and legal regulations with the use of the analytical, comparative and exegetical method, and after analyzing the relevant variables, concludes that prosecutors, like judges, are called or obligated to guarantee the Judicial Protection Effective, then, are responsible for ensuring compliance with this right of protection for the victim. When analyzing the variables that contain the problem, we can observe a possible violation of Effective Judicial Guardianship on the part of the Prosecutor based on a potential error in the assessment of the criminal type during the formulation of charges, which eventually affected by issues of prescription from the private exercise of the action the right of the victim to an effective Judicial Guardianship for the incorrect fiscal action.
\end{abstract}

Key Words: Effective Judicial Protection; Murder; Injuries; Attempt; Causal Nexus. 


\section{La vulneración a la tutela judicial efectiva por la imputación incorrecta de un \\ delito}

Vol. 3, núm. 1., (2019)

Briones Núñez Nicolás David; Ortiz Samaniego Juan Andrés; Suqui Romero Gabriel Yovany

\section{Introducción.}

La tesis central en la que se enfoca este artículo gira en torno a una pregunta esencial, ¿ $\mathrm{Se}$ podría vulnerar la Tutela Judicial Efectiva por la incorrecta imputación de un delito? Esto, sobre la base de la presencia de reglas que integran el ordenamiento jurídico objetivo y la correcta dirección hacia el debido proceso, y de riesgos que se toman en la carga acusatoria.

Los operadores de justicia tienen un único fin, llegar a la verdad. El derecho a la verdad, la misma Corte Interamericana de Derechos Humanos (en adelante Corte IDH) lo cifra como uno de los derechos de las víctimas o sus familiares para el "esclarecimiento de los hechos por medio de la investigación" (Caso Blanco Romero y Otros vs. Venezuela, 2015), además para "el acceso a la justicia y como una forma de reparación" (Caso Comunidad de Rio Negro vs. Guatemala, 2012). Estas referencias jurisprudenciales establecen la búsqueda de la verdad como una nueva concepción de justicia. Búsqueda que respecto de la justicia, se plantea como una necesidad por alcanzarla (Caso Masacre de Pueblo Bello, 2006), esto como deber del Estado "de investigar con seriedad, como deber jurídico y no como una simple gestión” (Caso Godínez Cruz vs. Honduras, 1989). De lo último se colige que el Estado por medio de los operadores de justicia tiene un único fin, la búsqueda de la verdad.

El poder punitivo es uno de los elementos más fuertes del orden estatal, de ahí la expresión de Lord Acton "el poder corrompe, y el poder absoluto, tiende a corromper absolutamente" (Lewis, 2000, pág. 1), de lo que se infiere que el poder debe de ser controlado. Ese control referido al ámbito del poder punitivo, se lo hace mediante la vigencia del principio 


\section{La vulneración a la tutela judicial efectiva por la imputación incorrecta de un delito}

Vol. 3, núm. 1., (2019)

Briones Núñez Nicolás David; Ortiz Samaniego Juan Andrés; Suqui Romero Gabriel Yovany de legalidad propio del Derecho penal y "a través de las teorías de la pena (absolutas y preventivas), (...)" (Zaffaroni, 2002).

Una visión hacia el espectro constitucional ecuatoriano nos permite observar el amplio margen garantista de los derechos, tanto individuales, como colectivos, en ese enfoque garantista "todo el ordenamiento jurídico se encuentra dirigido hacia a protección de derechos..." (Sentencia N. ${ }^{\circ}$ 045-11-SEP-CC, 2011)

Ya en la delimitación necesaria de los tipos, existe una vía bipartida entre dos de ellos: asesinato en grado de tentativa con resultado de lesiones y el delito de lesiones propiamente dicho, cuya similitud podría generar conflicto al optar por direccionarse hacia uno u otro, sobre todo en cuestiones de prescripción y también en el respeto a las garantías básicas del debido proceso que "representa el derecho constitucional de carácter procesal y sustentico, consignado para encontrar la eficacia judicial, puesto que es el llamado a (...) otorgar seguridad, tutela y protección para quien es o tiene la posibilidades de ser parte en un proceso" (Corte Constitucional del Ecuador, 2015, pág. 10). El debido proceso, aunque no es el eje central de la temática, nos da el perfilamiento para el análisis de la Tutela Judicial Efectiva resultante de un imperativo desarrollo, donde a lo largo de los párrafos siguientes, se podría encontrar una posible vulneración de derecho.

El único órgano capaz de comprender a la Tutela Judicial Efectiva en su totalidad y que a su vez está capacitado para interpretar su alcance es la Corte Constitucional del Ecuador (en adelante CCE) puesto que tiene capacidad de emitir jurisprudencia constitucional vinculante, ya que, de acuerdo a nuestra carta magna además de las atribuciones que le son conferidas por la ley 


\section{La vulneración a la tutela judicial efectiva por la imputación incorrecta de un \\ delito}

Vol. 3, núm. 1., (2019)

Briones Núñez Nicolás David; Ortiz Samaniego Juan Andrés; Suqui Romero Gabriel Yovany está ser la máxima instancia de interpretación a nivel constitucional, e inclusive de los tratados internacionales de derechos humanos que se encuentra ratificados por el Estado por medio de sus dictámenes y sentencias, y aquellas decisiones que tome tienen carácter vinculante. No obstante, como aquí se verá, la función judicial al igual que la fiscalía, son órganos judiciales y estos, están llamados a su observancia.

\section{Metodología.}

El presente estudio está sustentado en la revisión bibliográfica especializada, jurisprudencia y normativa legal con el empleo del método analítico, comparativo y exegético. Para ello se recurrió a medios electrónicos para obtener toda la información necesaria y realizar todos los análisis correspondientes para la determinación de las conclusiones necesarias y que sirva como porte para futuras investigaciones.

\section{Resultados.}

\section{La Tutela Judicial Efectiva}

La tutela judicial efectiva, en adelante (TJE), es una garantía que el Estado proporciona a todas a las personas para lograr la justicia, la que a su vez constituye el "orbe de los valores jurídicos, sensu stricto, se reduce a un valor único: la seguridad jurídica" (Millas, 1970), esa seguridad jurídica es la base de esa justicia transformadora que se traduce para los operadores de justicia en la búsqueda de la verdad, a ser demostrada en juicio.

Establecida en la Constitución de la República de Ecuador de 2008 en adelante (CRE), a la TJE se la puede entender desde dos perspectivas advertidas por la doctrina. Por una parte y 


\section{La vulneración a la tutela judicial efectiva por la imputación incorrecta de un delito}

Vol. 3, núm. 1., (2019)

Briones Núñez Nicolás David; Ortiz Samaniego Juan Andrés; Suqui Romero Gabriel Yovany

desde la óptica del individuo, se trata de "un instrumento indispensable para lograr la reparación de sus derechos e intereses, cuando estos se vean afectados por una actuación u omisión de una o varias personas privadas, físicas o jurídicas, o de un ente público, contraria al ordenamiento jurídico" (Carrasco Durán, 2014)a. En este caso como se nota, infiere una garantía o derecho que tiene la persona para efectivizar el acceso a la justicia. Por otro lado, y desde la óptica del Estado, es "el medio a través del cual la Constitución y las demás normas del ordenamiento jurídico se hacen efectivas, mediante su aplicación a situaciones particulares, en el marco de las controversias sometidas al conocimiento y la decisión de los órganos judiciales." (Carrasco Durán, 2014)b. Como se observa, la doctrina sugiere una doble visión, subjetiva y objetiva.

La CRE es el instrumento que efectiviza a la TJE como una garantía de contenido múltiple que protege derechos e intereses de todas las personas, lo que la torna amplia, por lo que, se hace necesario su división en tres momentos "el primero relacionado con el acceso a la justicia; el segundo con el desarrollo del proceso en estricto cumplimiento de la Constitución y la Ley y en un tiempo razonable, y el tercero en relación con la ejecución de la sentencia" (González Pérez, 2001, pág. 57), criterio además adoptado por la propia CCE como una síntesis que denota el contenido dividiéndola en 3 objetivos, acceso a la justicia "derecho esencial mediante el cual se garantiza el goce efectivo de los demás derechos y libertades" (Sentencia N. ${ }^{\circ}$ 133-17-SEP-CC, 2017)a, desarrollo de un proceso "que las autoridades jurisdiccionales en su rol de directores del proceso se encuentra en la obligación principal de velar, garantizar el cumplimiento irrestricto de las reglas del debido proceso de las partes intervinientes en el proceso" (Sentencia N. ${ }^{\circ}$ 133-17-SEP-CC, 2017)b y en relación con la ejecución de la sentencia, hecho que va más allá del cumplimiento de las resoluciones judiciales, el parámetro de justicia 


\section{La vulneración a la tutela judicial efectiva por la imputación incorrecta de un \\ delito}

Vol. 3, núm. 1., (2019)

Briones Núñez Nicolás David; Ortiz Samaniego Juan Andrés; Suqui Romero Gabriel Yovany implica algo más importante, algo que busca todo individuo al acceder a la justicia, una solución fundada en derecho.

La TJE al ser considerada como "una garantía constitucional que tiene por objeto tutelar los derechos de las personas frente a posible arbitrariedades" (Sentencia N. ${ }^{\circ} 050-15-\mathrm{SEP}-\mathrm{CC}$, 2015), se constituye como un derecho que tiene toda persona para acudir a los órganos judiciales competentes y obtener de ellos una contestación bajo las garantías del debido proceso, en este sentido el derecho se extiende a cualquier autoridad dentro del núcleo jurisdiccional ya que se “impone a los órganos del sistema de administración de justicia” (Sentencia No 088-14-SEP-CC, 2014). En este contexto, queda esclarecido que no solo es una atribución del juez, sino que involucra a todo el plano judicial, tanto a jueces, fiscales y a todo el sistema de administración de justicia, lo que la distingue, además, del debido proceso pese a estar íntimamente ligados.

El ciudadano acude ante los órganos judiciales pertinentes, y lo hace con la búsqueda de la protección jurídica de sus derechos, estas líneas cobran mayor importancia, si podemos ejemplificarla, en el Derecho penal, donde el Estado utiliza su poder en su forma más absoluta al imponer sanciones y castigar infracciones que atenten en contra de los derechos y libertades de todas las personas, pero, todo este poder está limitado por el principio de mínima intervención penal, que según el COIP "está legitimada siempre y cuando sea estrictamente necesaria para la protección de las personas. Constituye el último recurso, cuando no son suficientes los mecanismos extrapenales" (Código Organico Integral Penal, 2014). La afectación de estos principios, implica ir en contra y desestimar a los individuos a los que él debe la protección de sus derechos, ya sea actuando o dejando de actuar. En el sentido más puro, es la traducción de 


\section{La vulneración a la tutela judicial efectiva por la imputación incorrecta de un delito}

Vol. 3, núm. 1., (2019)

Briones Núñez Nicolás David; Ortiz Samaniego Juan Andrés; Suqui Romero Gabriel Yovany

optimizar y en lo que a doctrina se refiere "los derechos fundamentales tienen el carácter de principios y los principios son mandatos de optimización" (Alexy, 2004) El derecho contenido en la norma jurídica vigente o a su vez en la creación de nuevos contextos jurídicos, que concluyan con una resolución ajustada al derecho con un claro contenido de justicia.

Hay que tomar en cuenta que, en el sentido amplio, la TJE a partir del 2008 es un derecho de contenido múltiple, que conforme al art. 75 de la CRE, garantiza a toda persona el:

“(...) derecho al acceso gratuito a la justicia y a la tutela efectiva, imparcial y expedita de sus derechos e intereses, con sujeción a los principios de inmediación y celeridad; en ningún caso quedará en indefensión. El incumplimiento de las resoluciones judiciales será sancionado por la ley." (2008)

Finalmente, ha de advertirse que la TJE está íntimamente ligada con el sistema procesal porque se convierte en una guía para la "realización de la justicia. Las normas procesales consagrarán los principios de simplificación, uniformidad, eficacia, inmediación, celeridad y economía procesal, y harán efectivas las garantías del debido proceso. No se sacrificará la justicia por la sola omisión de formalidades.” (Constitución de la República del Ecuador, 2008).

Rol de los jueces y fiscales frente a la Tutela Judicial Efectiva

En base a lo hasta ahora analizado, y para ir perfilando el discurso académico hacia la consecución de los objetivos, cabe cuestionarse ¿Sobre quienes recae la obligación de hacer efectiva esa tutela judicial? 


\section{La vulneración a la tutela judicial efectiva por la imputación incorrecta de un \\ delito}

Vol. 3, núm. 1., (2019)

Briones Núñez Nicolás David; Ortiz Samaniego Juan Andrés; Suqui Romero Gabriel Yovany

El Código Orgánico de la Función Judicial (en adelante COFJ) en su artículo 23 establece que, "la Función Judicial, por intermedio de las juezas y jueces, tiene el deber fundamental de garantizar la TJE de los derechos declarados en la Constitución y en los instrumentos internacionales de derechos humanos o establecidos en las leyes(...)" (2009), al tomar en cuenta a la Función Judicial, debemos apreciar un nuevo esquema de "gerencia", ésta se encuentra integrada por la Corte Nacional de Justicia, las cortes, tribunales y juzgados, la justicia indígena, los métodos alternos de solución de conflictos y el consejo de la judicatura, esa composición incluye a los Agentes Fiscales, es entonces cuando el rol del Fiscal en el sistema penal acusatorio se activa, por consiguiente, es el Fiscal el encargado de dirigir, coordinar, controlar y ejercer toda la indagación e investigación, el cumplimiento de estas actividades permitirán el debido proceso dentro del juicio oral.

Un Estado Constitucional de Derechos y Justicia “(...) Se organiza en forma de república y se gobierna de manera descentralizada.” (Constitución de la República del Ecuador, 2008) producto de una carga ideológica más extensiva y protectora, obliga a un replanteo total para luego de un tiempo repetirlo con la intención de ir perfeccionando esta progresiva humanización del derecho hasta concebir a la Tutela Efectiva de derechos, dado su amplio espectro de protección, como el mecanismo constitucional que dota al Estado de una responsabilidad gigantesca, la de responder de manera jurídica, razonable, lógica y comprensible toda aquella pretensión que tengan las personas sobre una posible vulneración de un derecho.

Como se determinó en apartados previos, la idea de un desarrollo en cuanto a la tutela efectiva de derechos se nutre sustancialmente de la realización de otros principios constitucionales, como, 


\section{La vulneración a la tutela judicial efectiva por la imputación incorrecta de un delito}

Vol. 3, núm. 1., (2019)

Briones Núñez Nicolás David; Ortiz Samaniego Juan Andrés; Suqui Romero Gabriel Yovany

por ejemplo, el principio de acceso a la justicia, el que bajo lineamientos constitucionales es un derecho de protección, por ende, se constituye en "una herramienta para remover los obstáculos que se presentan cuando los demás derechos son ejercidos. Entre los derechos de protección encontramos el derecho al acceso a la justicia" (Ávila Santamaría, 2012)a; y el debido proceso entendido "como una garantía en cualquier proceso judicial, y administrativo; incluso que puede ser aplicado en cualquier ámbito, público o privado, y el debido proceso de las personas privadas de libertad" (Ávila Santamaría, 2012, pág. 108)b. En consecuencia, no se puede concebir a la Tutela Efectiva de Derechos sin la materialización de estos principios.

La dirección de la actividad procesal recae sobre el Juez como el garante de los derechos, esto se infiere de la jurisprudencia constitucional cuando se refiere a que “(...) los derechos de las personas tiene relación con el derecho de acceso a los órganos jurisdiccionales para que, luego de un proceso que observe las garantías mínimas establecidas en la Constitución y la ley" (Sentencia N. ${ }^{\circ}$ 117-14-SEP-CC, 2014).

La "función jurisdiccional es competencia primordial para jueces y juezas" (Caso del Tribunal Constitucional Vs. Perú, 2001) pero, esta se extiende a manera de incluir a "los fiscales, y las defensoras y defensores públicos que, desde sus respectivos roles, están vinculados a los procesos en los cuales el Estado realiza funciones dirigidas a garantizar el acceso a la justicia" (Comisión Interamericana de Derechos Humanos, 2013), de ahí que éstos están obligados a realizar actuaciones dentro de los procesos donde se discute sobre los derechos de las personas. Es decir, es tan importante la correcta investigación por parte del agente fiscal, así como la valoración probatoria por parte del Juez dentro de la etapa de juicio. 


\section{La vulneración a la tutela judicial efectiva por la imputación incorrecta de un \\ delito}

Vol. 3, núm. 1., (2019)

Briones Núnez Nicolás David; Ortiz Samaniego Juan Andrés; Suqui Romero Gabriel Yovany

Es imprescindible establecer que, además de todas las facultades que le son otorgadas por la CRE, en base al COFJ, el Fiscal es obligado a desempeñar su cargo de manera imparcial, actuando con objetividad y teniendo en cuenta la situación del procesado y de la víctima, dirigiendo las indagaciones previas al proceso penal, además direccionar y promover de oficio o en su defecto a petición de parte el actuar procesal; garantizando así la intervención de la defensa de los procesados; aportar pruebas de cargo y descargo, precautelando así la eficacia probatoria.

No obstante, ¿Qué tan cierta es esta falta de elementos de convicción y hasta qué punto deja de ser responsabilidad del agente fiscal como "responsable de la investigación penal" el que no se hayan recabado elementos de convicción necesarios? En base a la buena fe procesal y otorgando el beneficio de la duda, podríamos decir que esta petición amparada en la mínima intervención penal no vulneraria la tutela efectiva de derechos siempre y cuando esta imposibilidad de obtener elementos de convicción necesarios no sea desvirtuada con la aparición posterior de los mismos, lo que demostraría falta de diligencia procesal por parte del agente fiscal, vulnerando el debido proceso de esta reinterpretación de la tutela efectiva de derechos.

Como se advirtió supra, la TJE está dividida en "tres momentos", por ende, se efectiviza a través de todos los operadores de justicia en su diferente actuar, es decir, a) en el acceso a la justicia, cuando se da el reclamo de la persona a la protección de sus derechos vulnerados b) en la etapa pre-procesal, donde la Fiscalía deberá establecer los presupuestos indispensables para poder dar inicio al proceso penal y de esa manera sustanciar objetivamente el proceso, que dicho propiamente, "el principio de objetividad no es otra cosa sino la vinculación de la administración al principio de legalidad, es síntesis, todo su actuar debe realizarse a acorde a la ley" (García 


\section{La vulneración a la tutela judicial efectiva por la imputación incorrecta de un delito}

Vol. 3, núm. 1., (2019)

Briones Núñez Nicolás David; Ortiz Samaniego Juan Andrés; Suqui Romero Gabriel Yovany

Costa, 2011), finalmente la TJE se encuentra, c) en la ejecución de la respuesta fundada en derecho. Cómo ya pudimos establecer, la Fiscalía se encuentra involucrada dentro de los tres momentos, por lo tanto, está sus atribuciones como órgano de la función judicial, proteger el derecho a la TJE.

La CRE establece dentro las atribuciones de la Fiscalía una especial atención a todos los derechos de la víctima, en tal sentido el fiscal durante el proceso debe ejercer la acción penal pública respetando los principios orientadores del derecho penal y sobre todo atendiendo al interés público y derecho de las víctimas, entre los que se destacan, la TJE.

\section{Delito de lesiones versus asesinato en grado de tentativa}

Siguiendo la línea de nuestro ordenamiento jurídico el COIP, no establece una definición propia de lesiones simplemente se limita establecer el injusto cuando el art. 152 refiere "la persona que lesione a otra", y ya en sede doctrinaria, se la suele precisar como "un daño en el cuerpo o bien un daño en la salud" (Soler, 1945). Ese daño, bien estaría dado por "golpear, herir o maltratar de obra a otro" (Politoff, Matus, \& Ramirez , 2005), en esta ruta definiremos esos tres puntos: a) Herir, que se traduce en romper partes del cuerpo con un instrumento que penetre, lastime o corte extremidades, piel o partes del cuerpo, b) Golpear, consiste en el encuentro de dos cuerpos en el espacio en forma repentina y violenta y c) Maltratar, significando el sufrimiento o la intención de causarlo en una persona. (Obreque Oviedo, 2002). Al establecer que las lesiones son la intención de causar daño, la doctrina nos menciona que, "las lesiones son cualquier acto que ocasione en el cuerpo de otro algún daño o dolor físico, o perturbación en su mente; con tal que al ejecutarlo no haya intención de dar muerte, ni resultados letales.” (Zavala Baquerizo, 2005). 


\section{La vulneración a la tutela judicial efectiva por la imputación incorrecta de un \\ delito}

Vol. 3, núm. 1., (2019)

Briones Núñez Nicolás David; Ortiz Samaniego Juan Andrés; Suqui Romero Gabriel Yovany

Alonso de Escamilla, al referirse a las lesiones las considera como "El menoscabo de la integridad corporal o de la salud física o mental causado por cualquier medio o procedimiento" (2013)a, así se establece que cualquier daño a la salud por cualquier método se configura como una lesión; además "todo daño causado a la integridad corporal o a la salud de la persona por medios mecánicos, químicos y virulentos, o de cualquier orden materia.” (2013)b, ambos puntos establecen que cualquier daño a la salud o a la integridad física, se convierten en una lesión, la doctrina establece sobre el daño salud que, "un desorden en el equilibrio fisiológico es ya una alteración propia a la salud" (Reynoso Dávila, 2006), por ende, al ocasionar daño a la integridad física o a la salud, se creería que ya se encuadraría el tipo de lesiones, no obstante el hecho se materializa siempre y cuando sea sin intención de causar la muerte, puesto que la figura genérica del delito de lesiones tener la intención de causar daño en el cuerpo o un daño a la salud." (Labatut Glena, 2000) .

Respecto del bien o bienes jurídicos protegidos por el delito de lesiones, van desde la protección a la integridad física al evitar que en el cuerpo se cause un daño o dolor físico, hasta la protección psíquica, que significa la protección de perturbaciones mentales, siempre y cuando, como ya fue mencionado en líneas anteriores, no exista la intención de dar muerte o propiamente dicho, buscar resultados letales (Zavala Baquerizo, 2005). Además de estos indicadores, en nuestro ordenamiento jurídico se establece que protege hasta la integridad personal en general. En muchos de los casos, el daño físico constituye un doble daño no solo de carácter corpóreo sino también psicológico, el bien jurídico protegido en el delito de lesiones es la integridad y salud personal, puesto que al entendemos la doble vertiente del ser humano, física y mental (Sigüenza Bravo, 2003). Por su parte, la integridad corporal es un bien protegido, ya que desde el 


\section{La vulneración a la tutela judicial efectiva por la imputación incorrecta de un delito}

Vol. 3, núm. 1., (2019)

Briones Núñez Nicolás David; Ortiz Samaniego Juan Andrés; Suqui Romero Gabriel Yovany

punto de vista fisiológico, protege los órganos del ser humano, y desde el psicológico, el equilibro de la salud mental (Etcheberry, 1998).

El COIP en el Art. 152 señala cinco reglas que conforme a la gravedad aumentan la pena en caso de lesiones, gravedad que también sirve para perseguirlas penalmente ya como delito de acción pública, ya como delito de acción privada. En cuanto a los delitos de acción privada, estos se catalogan así porque no existe un interés de carácter público para el castigo de su autor. No tiene un relevancia en cuanto a la afectación general, son delitos que suelen tener a un particular ofendido, y es este, quien puede decidir sobre la conveniencia, u oportunidad de someter su situación a un proceso (Matusan Acuña, 2013), estas son las lesiones producidas a la víctima que ocasionen un daño, enfermedad o incapacidad de a) cuatro a ocho días o b) de nueve a treinta días, y de acuerdo a lo establecido en el art. 410 del COIP, esta acción corresponde únicamente a la víctima, mediante querella, entonces, la acción privada, se identifica como un derecho de carácter subjetivo que tienen cada ciudadano para la producir la iniciativa procesal, y una vez comenzada la misma, intervenir en carácter de acusadores. La acción privada "podría ser identificada como un derecho subjetivo de todos los ciudadanos a la iniciativa procesal penal y, una vez comenzado el proceso, a su intervención como acusadores en él” (Pérez Gil, 1997). Para los propósitos de este estudio en cuanto a la prescripción del ejercicio de la acción privada, en base a lo establecido en el COIP, la acción prescribirá en el plazo de seis meses, tiempo que se contará a partir del cometimiento del delito si no se ha iniciado proceso penal, prescripción se producirá transcurridos dos años a partir de la fecha de la citación de la querella. 


\section{La vulneración a la tutela judicial efectiva por la imputación incorrecta de un \\ delito}

Vol. 3, núm. 1., (2019)

Briones Núñez Nicolás David; Ortiz Samaniego Juan Andrés; Suqui Romero Gabriel Yovany

Las lesiones como delitos de acción pública le corresponde al Ministerio Publico, su impulso procesal de oficio (Matínez Brenes, 1981), ya que la acción pública es "aquella en la cual la iniciativa e impulso del proceso penal dependen del Fiscal" (Rombolá \& Reboiras, 2008). Las lesiones que caben dentro de este ejercicio corresponden a un daño incapacidad o enfermedad que van de treinta y uno a noventa días, que produzcan en la victima una enfermedad grave o una disminución de sus capacidades físicas o mentales que no superen los noventa días y las que produzcan enajenación mental, que se base en la nulidad de la inteligencia o la voluntad (Serrano Gómez, 1985), incluyendo, perdida del habla, inutilidad para el trabajo que según Rojas es el "daño que impide toda clase de trabajo, con independencia del oficio habitual del herido" (Chiappin, 2016). También aquellas que producen incapacidad permanente que disminuyan o anulen de alguna manera su capacidad laboral (Pardo, 2015). Además, pueden producir la pérdida o inutilización de algún órgano o alguna grave enfermedad transmisible e incurable.

De su lado, el asesinato sustancialmente mantiene una aparente similitud al delito de homicidio, que, en virtud de lo expresado por el COIP consiste en la muerte de una persona por parte de otra. Mientras que el homicidio doctrinariamente es la intención de causar la muerte y que la muerte sea el resultado que busca el sujeto activo (Torres Sandoval, 2014) sin la afluencia de sucesos perjudiciales, este tipo penal solo exige como resultado la muerte de otra persona, sin que exista algún otro elemento de tipo objetivo (Fernández Lavayen, 2017). Es decir, que no existan circunstancias que agraven el hecho, a diferencia del asesinato, que, siguiendo nuestro ordenamiento jurídico, la CCE nos dice que el asesinato existe cuando hay “(...) una mayor intensidad del propósito criminal, por los medios perjudiciales utilizados de un modo especial o por la inconfundible malicia y peligrosidad que se revela; por todo ello, con acierto se señala que 


\section{La vulneración a la tutela judicial efectiva por la imputación incorrecta de un delito}

Vol. 3, núm. 1., (2019)

Briones Núñez Nicolás David; Ortiz Samaniego Juan Andrés; Suqui Romero Gabriel Yovany

no existe el asesinato imprudente, ya que lleva siempre aparejada la intencionalidad." (Sentencia

No. ${ }^{\circ}$ 171-16-SEP-CC, 2016). El COIP en el artículo 140 establece diez circunstancias para que

el homicidio sea sancionado como asesinato.

El bien jurídico que protege el asesinato es el mismo que protege el homicidio, el derecho a la vida, la Convención Americana sobre Derechos Humanos establece que "Toda persona tiene derecho a que se respete su vida. Este derecho estará protegido por la ley y, en general, a partir del momento de la concepción. Nadie puede ser privado de la vida arbitrariamente" (2014)

Al hablar de la posible vulneración en la protección del bien jurídico, en el caso del asesinato departimos sobre la protección al derecho a la vida y en las lesiones a la integridad personal, y como manifiesta Aguilar, "la víctima se halla estrechamente unida al bien jurídico, al ser ella quien sufre directamente la acción u omisión lesiva" (2009). Sin duda, la doctrina ha establecido diferentes concepciones, en ese sentido, para Mendelsonhn, la víctima incluye al "individuo o colectividad en la medida en que está afectada por las consecuencias sociales de sufrimiento, determinado por factores de origen muy diverso, físico, psíquico, económico, político o social; así como el ambiente natural o técnico" (1981)

Pero, ¿Qué pasaría si el asesinato no llega a consumarse?, en este caso, hablaríamos de una tentativa en cuanto a la vulneración del bien jurídico que se pretende proteger. La tentativa es "la no realización del hecho punible por circunstancias o contingencias ajenas a la voluntad del agente" (Vásquez Abad, 1962), con la tentativa de asesinato se estaría cumpliendo la parte subjetiva del tipo, esto sería actuar con dolo, es decir, con el pleno conocimiento de los hechos y la voluntad realizar los mismos (Díaz Pérez, 2010), en consecuencia, si no existe el dolo, que en 


\section{La vulneración a la tutela judicial efectiva por la imputación incorrecta de un \\ delito}

Vol. 3, núm. 1., (2019)

Briones Núñez Nicolás David; Ortiz Samaniego Juan Andrés; Suqui Romero Gabriel Yovany

el caso de asesinato sería la intención de matar o los indicios claros que establezcan la finalidad de provocar este resultado, no hay tentativa.

Respeto del bien jurídico en el asesinato, existe uniformidad en afirmarse que es el derecho a la vida y en las lesiones a la integridad personal. La víctima se halla estrechamente unida al bien jurídico, puesto que es ella quien sufre directamente la acción u omisión de carácter lesivo (Aguilar, 2009). Sin duda, la doctrina ha establecido diferentes concepciones. Así, para Mendelsonhn, víctima es "individuo o colectividad en la medida en que está afectada por las consecuencias sociales de sufrimiento, determinado por factores de origen muy diverso, físico, psíquico, económico, político o social; así como el ambiente natural o técnico" (1981), la víctima se caracteriza por el rol que desempeña desde el momento la denuncia inicial y en su participación a lo largo del proceso penal como testigo" (Cuarezma Terán, 1996).

Es evidente que, a fin de que se atribuya el cometimiento del delito exista una relación de causalidad, sin nexo causal el resultado aparecería como un acontecimiento totalmente aislado y errático del comportamiento del sujeto y sin que el mismo tenga relación alguna (Suprema Corte de Justicia de la Nación Mexicana, 2018). En nuestro ordenamiento jurídico, el COIP plantea que, los elementos probatorios deberán tener un nexo causal entre la infracción y la persona procesada.

Analizados los aspectos de cada tipo penal, el bien jurídico protegido y el nexo causal, deviene una pregunta, ¿Qué tan determinante es la consideración de las lesiones y las circunstancias de los hechos para decidirse, por el tipo de lesiones o por el asesinato en grado de tentativa? Para dar respuesta a esta interrogante hay que demarcar la intención del agente a la hora de realizar el 


\section{La vulneración a la tutela judicial efectiva por la imputación incorrecta de un delito}

Vol. 3, núm. 1., (2019)

Briones Núñez Nicolás David; Ortiz Samaniego Juan Andrés; Suqui Romero Gabriel Yovany injusto del tipo, Serrano sostiene que "la realización de las lesiones de determinada forma “(...) no determina necesariamente que cobren perfil propio con respecto al marco del atentado contra la vida" (2009), es decir que no necesariamente las lesiones atentan contra la vida como para no diferenciarlas de un homicidio o asesinato, pero, si la voluntad es matar y no se logra por cuestiones externas ajenas a la voluntad de algente, y si de hecho solo le causare lesiones, dado la intención dolosa dirigida al bien jurídico vida, sería asesinato en grado de tentativa. Entonces, se colige que se trata de dos conductas penales diferentes y autónomas a la hora de su imputación, que, de presentarse conjuntas, fuera de los casos de tentativa, serán objeto de análisis a la luz de los concursos de infracciones.

La situación legal de las lesiones va a depender de su gravedad, la que a la postre va a ser que este delito se ubique o dentro de los delitos del ejercicio público de la acción, o dentro de los del ejercicio privado de la acción penal

Por otra parte, se ha de advertir que, la acción penal privada engloba un tipo específico de lesiones que son las constituyentes de a) 4 a 8 días y, b) de 9 a 30 días de incapacidad, estas se encuentran incluidas en este aparado por depender directamente "de la voluntad del accionante, de ninguna manera podría extenderse a delitos que por su íntima relación con la persona, la existencia humana o su elevado impacto social, no son susceptibles de disposición, como pueden ser la vida" (Chaves Peña, 2013). Es decir, estas lesiones tienen la característica de encontrarse como las menos lesivas a la persona, para optar por el asesinato en grado de tentativa, las lesiones deben ser proporcionales al objetivo de afectar la integridad física al punto de provocar la muerte, esto es demostrable mediante el informe médico legal, que según Yávar "las versiones 


\section{La vulneración a la tutela judicial efectiva por la imputación incorrecta de un \\ delito}

Vol. 3, núm. 1., (2019)

Briones Núñez Nicolás David; Ortiz Samaniego Juan Andrés; Suqui Romero Gabriel Yovany recogidas por parte de la víctima no constituyen prueba suficiente para que el fiscal acuse, por lo que dicha declaración debe estar soportada por el informe pericial que establece su hubo o no la materialidad de la infracción y las distintas circunstancias en la que se realizó" (1997), para que exista una clara tentativa de asesinato se debe de haber empleado los actos idóneos con el fin de dar muerte ya que ese es el propósito del asesinato, el delito no se funda en el resultado sino en la intención de dar muerte; en el delito de lesiones la intención como propósito final es dañara la integridad corporal sin la intención de acabar con la vida, la naturaleza de las lesiones inferidas marcan un clara intención de lo que el autor quiso hacer.

\section{Conclusiones}

La TJE es un derecho que comprende un amplio espectro de protección con reconocimiento en la Constitución de Ecuador. Reconocimiento que se debe en parte a la fuerte carga dogmática que introdujo el garantismo como motor ideológico de la Carta Magna. Esta nueva concepción se encuentra repotenciada por el sistema jurídico ecuatoriano, lo que conlleva que esta garantía este inmersa dentro de los procesos donde se vean involucrados los derechos de las personas, por lo que, es correcto concluir que la TJE es un derecho que debe estar presente para los usuarios del sistema penal en las etapas de acceso, proceso y respuesta fundada en derecho, misma que debe cumplirse.

La normativa constitucional y legal ecuatoriana exige a los jueces la obligación de velar por el ejercicio de esa tutela, pero también al determinar al fiscal como parte de la función judicial, le compete a éste ejercitar su cumplimiento en sede penal. $\mathrm{Y}$ es que precisamente, entre las obligaciones de la fiscalía está la de acusar delitos de acción pública, lo que conlleva a una 


\section{La vulneración a la tutela judicial efectiva por la imputación incorrecta de un delito}

Vol. 3, núm. 1., (2019)

Briones Núñez Nicolás David; Ortiz Samaniego Juan Andrés; Suqui Romero Gabriel Yovany

observación directa del acceso a la tutela judicial. Pero también la fiscalía debe guardar observancia de los principios procesales garantizados en el art. 5 del COIP, entre ellos el de objetividad que le permitirá acusar, pero también abstenerse de hacerlo cuando la evidencia así lo establezca.

En ejercicio del deber de acusar en nombre de la sociedad, el fiscal requiere preparación constante cualificada toda vez que en sus manos está la carga de la prueba, por ende, su actuación debe ser observando dos cuestiones: a) "tino" para que apenas tenga conocimiento de un posible delito en donde la víctima no ha podido determinar si se trata de uno de acción pública o privada, si la situación o los hechos son confusos u oscuros, disponer diligencias inmediatas para visualizar la naturaleza del delito y el ejercicio de la acción y por ende disponer su inicio o no como ejercicio público. Y esto porque si se trata por ejemplo, de un delito de lesiones que no superen los 30 días, que por ende deba sustanciarse al amparo de la acción privada, puede afectar los plazos de la prescripción; y por otro lado b) si de todos modos, dado la complejidad del caso, no ha podido diferenciar al delito entre la acción pública o privada cuando uno de ellos se lo ejercita en las dos vías como las lesiones o usurpación, por ejemplo-, la prontitud para evacuar diligencias tendientes a su esclarecimiento a fin de precautelar también los derecho de la víctima para que pueda enderezar su accionar por la vía correcta.

En conclusión, aunque no sea obligación exclusiva de la fiscalía asesorar o enmendar errores de los usuarios concretamente de las víctimas de delitos, sí le compete actuar con conocimiento, prontitud y de forma diligente para que como consecuencia de su accionar no quede la víctima sin poder reclamar su derecho cuando la fiscalía ha asumido competencias que no le competen y 


\section{La vulneración a la tutela judicial efectiva por la imputación incorrecta de un}

delito

Vol. 3, núm. 1., (2019)

Briones Núñez Nicolás David; Ortiz Samaniego Juan Andrés; Suqui Romero Gabriel Yovany

lo que es más, no ha actuado diligentemente para dejar a salvo los derechos. Es en estos casos donde se tensa con ese actuar de fiscalía, la TJE.

\section{Bibliografía}

Aguilar, L. F. (2009). Bien Jurídico, víctima y sanción penal. Auctoritas Prudentium. Obtenido de Bien jurídico, víctima y sanción penal: http://www.unis.edu.gt/ap/fetch/bien-juridicovictima-derecho-penal.pdf

Alexy, R. (2004). Epílogo a la Teoría de los derechos fundamentales. (C. B. Pulido, Trad.) Madrid, España: Colegio de Registradores de la Propiedad, Mercantiles y de Bienes Muebles.

Alonso de Escamilla, A. (2013). Delitos y Faltas, La Parte Especial del Derecho Penal (Segunda ed.). Madrid: Colex.

Asamblea Nacional del Ecuador. (2008). Constitución de la República del Ecuador. Quito, Ecuador.

Asamblea Nacional del Ecuador. (2009). Código Orgánico de la Función Judicial. Quito: Asamblea Nacional del Ecuador.

Ávila Santamaría, R. (2012). Los Derechos y sus Garantías. Quito: Centro de Estudios y Difusión del Derecho Constitucional (CEDEC).

Carrasco Durán, M. (2014). Jurisdicción constitucional y derecho a la tutela judicial efectiva sin indefensión. Navarra, España: Arazandi.

Caso Blanco Romero y Otros vs. Venezuela, C 138 (Corte Interamericana de Derechos Humanos 28 de Noviembre de 2015).

Caso Comunidad de Rio Negro vs. Guatemala, C 194 (Corte Interamericana de Derechos Humanos 04 de Septiembre de 2012).

Caso del Tribunal Constitucional Vs. Perú (Corte Interamericana de Derechos Humanos 31 de Enero de 2001).

Caso Godínez Cruz vs. Honduras, C 5 (Corte Interamericana de Derechos Humanos 20 de Enero de 1989).

Caso Masacre de Pueblo Bello, C 140 (Corte Interamericana de Derechos Humanos 31 de Enero de 2006). 


\section{La vulneración a la tutela judicial efectiva por la imputación incorrecta de un delito}

Vol. 3, núm. 1., (2019)

Briones Núñez Nicolás David; Ortiz Samaniego Juan Andrés; Suqui Romero Gabriel Yovany

Chaves Peña, E. M. (Enero-Junio de 2013). La Acción Penal Privada y su implementación en Colombia. Via Iuris(14), 167-185.

Chiappin, J. E. (19 de Septiembre de 2016). La inutilidad para el trabajo cuando el delito de lesiones. $\quad E l \quad$ Derecho, 1-8. Obtenido de http://www.elderecho.com.ar/includes/pdf/diarios/2016/09/19092016.pdf

Comisión Interamericana de Derechos Humanos. (2013). Garantías para la Independencia de las y los operadores de justicia. Hacia el fortalecimiento del acceso a la justicia y el estado de derecho en las américas. Obtenido de https://www.oas.org/es/cidh/defensores/docs/pdf/operadores-de-justicia-2013.pdf

Corte Constitucional del Ecuador, 1567-13-EP (Corte Constitucional del Ecuador 25 de Marzo de 2015).

Cuarezma Terán, S. J. (1996). La Victimología. San José: Instituto Interamericano de Derechos Humanos.

Díaz Pérez, N. C. (enero-junio de 2010). Discusión jurisprudencial sobre el dolo eventual y la culpa con representación en delitos de homicidio ocasionados en accidentes de tránsito. Logos Ciencia \&Tecnología, 1(2), 184-194.

Ediciones Legales. (2014). Código Organico Integral Penal. Quito: Ediciones legales.

Etcheberry, A. (1998). Derecho Penal, Parte Especial (Tercera ed.). Santiago de Chile, Chile: Jurídica de Chile.

Fernández Lavayen, L. (2017). La Respuesta Judicial del Femicidio en Ecuador. Quito: Artes Gráficas SILVA.

García Costa, F. M. (enero-abril de 2011). Delimitación conceptual del principio de objetividad: objetividad, neutralidad e imparcialidad. Documentación Administrativa(289), 21-42.

González Pérez, J. (2001). El Derecho a la Tutela Jurisdiccional (Tercera ed.). Madrid: Civitas Ediciones.

Labatut Glena, G. (2000). Derecho Penal, Parte Especial. Tomo II (Séptima ed.). (J. Z. Vargas, Ed.) Santiago de Chile: Jurídica de Chile.

Lewis, L. S. (Mayo de 2000). When Power Corrupts: Academic Governing Boards in the Shadow of the Adelphi Case. New Brunswick.

Matínez Brenes, L. (1981). CijulenLinea. Obtenido de La Acción Penal Pública: www.pensamientopenal.com.ar/system/files/2017/02/doctrina44859.pdf 


\section{La vulneración a la tutela judicial efectiva por la imputación incorrecta de un}

delito

Vol. 3, núm. 1., (2019)

Briones Núñez Nicolás David; Ortiz Samaniego Juan Andrés; Suqui Romero Gabriel Yovany

Matusan Acuña, C. (2013). La Acción Penal Privada y la afectación de derechos fundamentales. VIA IURIS(14), 187-197. Obtenido de https://www.redalyc.org/articulo.oa?id=273929754011

Mendelsohn, B. (Abril de 1981). La victimologia y las tendencias de la sociedad contemporanea. ILANUD al día , 4(10), 55-67.

Millas, J. (1970). Filosofía del derecho. Santiago : Lex.

Obreque Oviedo, C. S. (2002). Repositorio de la Universidad de Chile. Obtenido de http://repositorio.uchile.cl/bitstream/handle/2250/107315/Del\%20delito\%20de\%20lesion es $\% 20 \mathrm{y} \% 20 \mathrm{en} \% 20$ particular\%20de $\% 20 \mathrm{las} \% 20$ causadas\%20por\%20armas.pdf?sequence $=3$

Pardo, J. M. (2015). La Incapacidad laboral como indicador de gestión sanitaria. Medicina y Seguridad del Trabajo, 207-219.

Pérez Gil, J. (1997). La Acusación Particular. Valladolid: Departamento de Derecho Constitucional, Procesal y Eclesiástico.

Politoff, S., Matus, J. P., \& Ramirez , C. (2005). Lecciones de Derecho Penal, Parte Especial (Segunda ed.). Santiago de Chile: Jurídica.

Reynoso Dávila, R. (2006). Delitos contra la Vida y la Integridad Corporal. Mexico: Porrua.

Rombolá, N., \& Reboiras, L. M. (2008). Diccionario Ruy Díaz de Ciencias Jurídicas y Sociales. Buenos Aires: DISELI.

Sentencia N. ${ }^{\circ}$ 045-11-SEP-CC, 0385-11-EP (Corte Constitucional 24 de Septiembre de 2011).

Sentencia N. ${ }^{\circ}$ 050-15-SEP-CC, 1887-12-EP (Corte Constitucional de Ecuador 25 de Febrero de 2015).

Sentencia N. ${ }^{\circ}$ 117-14-SEP-CC, 1010-11-EP (Corte Consitucional del Ecuador 06 de Agosto de 2014).

Sentencia N. ${ }^{\circ}$ 133-17-SEP-CC, 0288-12-EP (Corte Constitucional del Ecuador 10 de Mayo de 2017).

Sentencia No 088-14-SEP-CC, 0811-12-EP (Corte Constitucional del Ecuador 21 de Mayo de 2014).

Sentencia No. ${ }^{\circ}$ 171-16-SEP-CC, 0854-15-EP (Corte Constitucional del Ecuador 25 de Mayo de 2016).

Serrano Gómez, A. (1985). Enajenación mental y trastorno mental transitorio. e-Spacio, 29-45. 


\section{La vulneración a la tutela judicial efectiva por la imputación incorrecta de un delito}

Vol. 3, núm. 1., (2019)

Briones Núñez Nicolás David; Ortiz Samaniego Juan Andrés; Suqui Romero Gabriel Yovany

Serrano González de Murillo, J. L. (Julio de 2009). La tentativa de homicidio con consumación de lesiones. Doctrina(24), 177-186. Obtenido de http://rabida.uhu.es/dspace/bitstream/handle/10272/11887/Tentativa.pdf?sequence=2

Sigüenza Bravo, M. (2003). Derecho Penal, Parte Especial (Vol. I). Cuenca, Ecuador: Sigma.

Soler, S. (1945). Derecho Penal Argentino. Buenos Aires: Tea.

Suprema Corte de Justicia de la Nación. (2014). Convención Americana sobre Derechos Humanos comentada (Primera ed.). (N. Hernández Beltrán, \& G. Rivera Rodríguez, Edits.) Distrito Federal, México: Fundación Konrad Adenauer. Programa Estado de Derecho para Latinoamérica. Obtenido de http://www.corteidh.or.cr/tablas/30237.pdf

Suprema Corte de Justicia de la Nación Mexicana. (Noviembre de 2018). Suprema Corte de Justicia de Mexico. Obtenido de Semanario Judicial de la Federación y su Gaceta: https://sjf.scjn.gob.mx/sjfsist/Paginas/DetalleGeneralScroll.aspx?id=1380\&Clase=Votos DetalleBL

Torres Sandoval, J. (2014). Delito de abandono de personas desvalidas. Revista de Derecho de la Pontificia Universidad Católica de Valparaíso, 261 - 294.

Vásquez Abad, Á. M. (1962). Iter criminis - tentativa y delito frustrado. Univesidad Pontificia, $25(91), 433-456$.

Yávar Núñez, F. (1997). Los delincuentes sexuales y el abuso infantil. PUDELECO .

Zaffaroni, E. R. (2002). Derecho Penal. Parte General. Buenos Aires: Ediar.

Zavala Baquerizo, J. (2005). Delitos contra las Personas. Tomo II. Quito, Ecuador: Edino. 